\title{
AVALIAÇÃO FITOTECNICA DE BANANEIRAS TIPO TERRA SOB IRRIGAÇÃO EM CONDIÇÕES SEMI-ÁRIDAS
}

\author{
Agronomical evaluation of bananas under irrigation and semi-arid conditions
}

\author{
Hudson Caldeira de Faria ${ }^{1}$, Sérgio Luiz Rodrigues Donato ${ }^{2}$, \\ Marlon Cristian Toledo Pereira ${ }^{3}$, Sebastião de Oliveira e Silva ${ }^{4}$
}

\begin{abstract}
RESUMO
Conduziu-se este trabalho, com o objetivo de avaliar fitotecnicamente as características vegetativas e de rendimento de cinco cultivares de bananeira tipo Terra, em primeiro ciclo de produção sob irrigação nas condições semiáridas da região de Guanambi - BA. Utilizaram-se descritores fenotípicos relevantes para a identificação e seleção de indivíduos com características superiores, visando a disponibilizar aos produtores dos perímetros de irrigação uma alternativa para a diversificação da bananicultura. Avaliaram-se as seguintes características: número de dias do plantio ao florescimento e à colheita, altura da planta, perímetro do pseudocaule, número de folhas vivas nas épocas do florescimento e colheita, o intervalo florescimento-colheita, peso do cacho, da ráquis e das pencas, número de pencas e de frutos, comprimento e diâmetro do fruto. O experimento foi delineado em blocos casualizados, com cinco tratamentos, constituídos pelas cultivares AAB: Terra, Terra-Maranhão, Terrinha e D’Angola e pelo híbrido AAAB: FHIA-21 com cinco repetições. Cada parcela foi constituída por 20 plantas (quatro fileiras de cinco plantas), com seis plantas úteis no espaçamento de 3,0 m x 3,0 m. Destacaram-se as cultivares avaliadas a Terra e a Terra Maranhão como as mais produtivas, porém, com maior altura e mais tardias em ciclo. O híbrido FHIA-21 e as cultivares Terrinha e D’Angola, apresentaram-se com maior número de folhas vivas à época da colheita. A cultivar D’Angola apresentou a menor produtividade dentre as cultivares avaliadas.
\end{abstract}

Termos para indexação: Plátanos, perímetros de irrigação, banana de cozinhar, Musa.

\begin{abstract}
The goal of this work was to make a agronomical evaluation of the vegetative characteristics and income of five cultivars of banana type Plantain, in the first production cycle under irrigation in the semi-arid conditions of the region of the city of Guanambi Bahia State. Relevant phenotypic descriptors were used for the identification and selection of individuals with superior characteristics, so as to make available to the producers of the perimeters of irrigation an alternative for the diversification of the banana crops. The evaluated genotypes AAB were the varieties Terra, Terra-Maranhão, Terrinha and D'Angola and the hybrid AAAB: FHIA-21. The following characteristics were analyzed: number of days from the sowing to the flowering and to the harvest, height of the plant, perimeter of the pseudostem, number of alive leaves at flowering and harvest, gap flowering-harvest, weight of the bunch, of the peduncle and of the hands, number of hands and fruits per bunch, length and diameter of the fruit. The procedure employed was randomized blocks, with five treatments, consisting of the cultivars AAB: Terra, Terra-Maranhão, Terrinha and D'Angola and the hybrid AAAB: FHIA-21, and five repetitions. Each plot was comprised by 20 plants: four rows of five plants, with six useful plants in the spacing of 3,0 m x 3,0 m. Terra and Terra Maranhão were the most productive varieties, however, with larger load and late cycles. The hybrid FHIA-21 and the varieties Terrinha and D'Angola showed a larger number of living leaves in the harvest. The variety D'Angola presented the smallest productivity between the evaluated cultivars.
\end{abstract}

Index terms: Plantain, irrigated perimeters, banana for cooking, Musa.

(Recebido em 8 de outubro de 2008 e aprovado em 30 de outubro de 2009)

\section{INTRODUÇÃO}

Os plátanos, bananas da Terra, ou bananas de cozinhar (Musa spp., grupo AAB e AAAB) constituem-se num dos principais cultivos amiláceos nos países em desenvolvimento e, em conjunto com a banana, para consumo in natura, são as frutas mais produzidas e consumidas mundialmente. A Índia, Uganda, Equador e o
Brasil são os principais países produtores e representam cerca de $50 \%$ da produção mundial de bananas e plátanos (Food and Agricultural Organization-FAO, 2008). O continente africano é um grande produtor e consumidor de banana, onde a fruta é usada como alimento energético em substituição ao pão (Moreira, 1999) e também como fruta de sobremesa (Dadzie \& Orchard, 1997).

\footnotetext{
${ }^{1}$ Companhia de Desenvolvimento dos Vales do são Francisco e do Parnaíba/CODEVASF - 2ª Superintendência Regional - $2^{\circ}$ Escritório de Apoio Técnico - 46.430-000 - Avenida Deolinda Martins - 166 - Guanambi,BA - hudson.faria@codevasf.gov.br

2Escola Agrotécnica Federal Antônio José Teixeira - Distrito de Ceraíma - Guanambi/BA

${ }^{3}$ Universidade Estadual de Montes Claros - Departamento de Ciências Agrárias - Centro de Ciências Exatas e Tecnológicas - Janaúba/MG

${ }^{4}$ Embrapa Mandioca e Fruticultura Tropical - Cruz das Almas/BA
}

Ciênc. agrotec., Lavras, v. 34, n. 4, p. 830-836, jul./ago., 2010 
No Brasil, as regiões Nordeste e Norte concentram os maiores plantios de banana tipo Terra com destaque para os estados de Alagoas e Bahia, onde é mais expressiva na região do Recôncavo Baiano, fazendo parte do hábito alimentar das populações nortista e nordestina. Contudo, não existem dados sobre a quantidade produzida, cultivares e rendimento obtido (Borges et al., 2002).

Regionalmente, a bananicultura contribui para mudar, econômica e socialmente, as áreas carentes do semiárido brasileiro. Conforme dados da Companhia de Desenvolvimento dos Vales do São Francisco e do ParnaíbaCODEVASF (2007), os Perímetros Públicos de Irrigação perfazem juntos 53.130 hectares irrigados em operação, dos quais 30.983 hectares ocupados com a bananicultura comercial. Na região semiárida, as condições climáticas, associadas ao manejo adequado da irrigação, proporcionam o cultivo de plátanos com baixa incidência de doenças, com oferta regular e boa qualidade de frutos.

As bananeiras desse subgrupo apresentam frutos grandes e alto teor de amido, suscetíveis à Sigatoka-negra, razoavelmente resistentes à Sigatoka-amarela, tolerantes ao mal-do-Panamá, medianamente prejudicadas pelos nematóides e altamente perseguidas pela broca-do-rizoma. Seus bananais têm vida curta; geralmente se colhe a "mãe" com boa produção, o "filho" mediano e o "neto" produz muito pouco, decorrente, principalmente, da presença do "moleque da bananeira" (Moreira, 1999).

Apesar dos esforços empreendidos para o melhoramento da bananeira e plátanos a partir de germoplasma natural selecionado pelo homem (Donato, 2003), o Brasil dedica pouca importância aos plátanos, embora exista um manual sobre o tema (Alves \& Lima, 2001), faltam informações precisas do cultivo desse tipo de banana, e o uso de tecnologias de produção é extrapolado a partir de outras cultivares.

Objetivou-se, com este trabalho avaliar fitotecnicamente as características vegetativas e de rendimento e o comportamento de cinco cultivares de bananeira tipo Terra, em primeiro ciclo de produção sob irrigação nas condições semiáridas da região de Guanambi - Bahia.

\section{MATERIAL E MÉTODOS}

O trabalho foi implantado em Latossolo VermelhoAmarelo distrófico, típico A fraco, textura média fase caatinga hipoxerófila, relevo plano a suave ondulado, na área experimental da Escola Agrotécnica Federal Antônio José Teixeira, no município de Guanambi, com latitude de $14^{\circ} 13^{\prime} 30^{\prime \prime}$ sul, longitude de $42^{\circ} 46^{\prime} 53^{\prime \prime}$ oeste e altitude de $525 \mathrm{~m}$. As médias anuais de precipitação pluvial é de $663,69 \mathrm{~mm}$ e a temperatura média e a umidade relativa do ar são de $26^{\circ} \mathrm{C}$ e 64\%, respectivamente (Donato et al., 2006).
$\mathrm{O}$ experimento foi instalado com mudas micropropagadas cedidas pela Embrapa Mandioca e Fruticultura Tropical, multiplicadas pela empresa Campo Biotecnologia em Cruz das Almas-BA, transportadas para o local do experimento em embalagens tipo rocambole, onde foram plantadas em sacos de polietileno de $15 \mathrm{~cm} \times 25 \mathrm{~cm}$, contendo substrato apropriado e aclimatadas em telado (sombrite 50\%), por cerca de 30 dias.

O sistema de irrigação utilizado foi do tipo aspersão convencional fixo, com aspersores subcopa, com lâmina total aplicada no ciclo igual a $2.047 \mathrm{~mm}$, suplementar a precipitação média anual. O manejo de irrigação foi calculado pelo método do turno de rega pré-fixado diário, baseado nas características condições atmosféricas (dados de Et0 do Tanque Classe A e de temperatura medidos na Estação Meteorológica da CODEVASF em Ceraíma, próxima ao local do experimento), nas características do sistema de irrigação (vazão e espaçamento entre aspersores) e nos coeficientes de cultivo da cultura em função da sua fase de desenvolvimento (Doorenbos \& Kassan, 1994; Coelho et al., 2001).

No dimensionamento do sistema, foram consideradas as seguintes características físicohídricas do solo: Capacidade de Campo = 15,40 p p-1; Ponto de Murcha $=$ 7,10 p p-1 e Densidade Aparente = 1,82 g cm-3, determinadas por análises, e profundidade do sistema radicular (Praizes) igual a $400 \mathrm{~mm}$. A disponibilidade total de água no solo, calculada pela fórmula DAS $=(\mathrm{Ucc}-\mathrm{Upmp}) \times$ Ds x Praizes, foi de $60,42 \mathrm{~mm}$. A lâmina liquida diária entre irrigações, para todas as cultivares (tratamentos), calculada pela fórmula $\mathrm{LI}=($ ?ECA $* \mathrm{Kt} * \mathrm{Kc}) / \mathrm{Ea}$ foi de $9,85 \mathrm{~mm}$, sendo ?ECA $=10,87 \mathrm{~mm} ; \mathrm{Kt}=0,70 ; \mathrm{Kc}=1,1$ (Doorenbos \& Kassan, 1994; Coelho et al., 2001) e Ea $=85 \%$ (Bernardo et al., 2006). O tempo de aplicação de água calculado pela fórmula $\mathrm{Ta}=$ (LI x Área Irrigada)/qaspersor, foi de 1,25 horas, sendo a área irrigada por aspersor de $144 \mathrm{~m} 2$ e qaspersor igual a $1.134 \mathrm{~m} 3 / \mathrm{h}$.

Os tratos culturais utilizados foram baseados nas recomendações técnicas apresentadas por Alves et al. (1997), Moreira (1999) e Alves (2001) e as adubações realizadas mediante análises de solo e de folha.

O delineamento experimental foi em blocos casualizados com cinco tratamentos, constituídos pelas cultivares AAB: Terra, Terra-Maranhão, Terrinha e D’Angola e pelo híbrido AAAB: FHIA-21 (Tabela 1), com cinco repetições, perfazendo 25 unidades experimentais. Cada parcela foi constituída por 20 plantas (quatro fileiras de cinco plantas), com seis plantas úteis e espaçamento de 3,0 m x 3,0 m. Contornando as parcelas úteis, foram plantadas mudas da cultivar Terrinha utilizadas como bordadura para todo o experimento. Os dados obtidos 
foram submetidos à análise de variância e as médias de cada tratamento comparadas pelo teste de Tukey a 5\% de probabilidade.

As cinco cultivares foram avaliadas em primeiro ciclo de produção, sendo observados os caracteres nos estádios de florescimento e colheita do cacho de cada planta útil, descritos a seguir: altura da planta; perímetro do pseudocaule; número de dias do plantio ao florescimento; número de folhas vivas no florescimento; número de dias do plantio à colheita do cacho; número de folhas vivas na colheita; peso do cacho e peso das pencas; número de frutos por cacho; peso médio do fruto, determinado no fruto central da fileira externa de frutos da segunda penca; comprimento externo do fruto, medido na curvatura externa do fruto central da segunda penca; diâmetro ou calibração lateral do fruto medida na parte mediana, no sentido do comprimento do fruto central da segunda penca (Donato et al., 2006).

\section{RESULTADOS E DISCUSSÃO}

Os resultados dos descritores fenotipicos avaliados demonstraram diferenças significativas entre as cinco cultivares para as características avaliadas na época do florescimento (Tabela 2), uma vez que o híbrido FHIA-21 foi desenvolvido por melhoramento genético (hibridação) para atender as características de um ideotipo varietal (menor porte e resistência a doenças), enquanto as demais são cultivares antigas selecionadas de forma empírica por bananicultores. As cultivares Terra e Terra-Maranhão apresentaram valores médios superiores as demais cultivares.

Tabela 1 - Descrição das cultivares tipo Terra avaliadas na Escola Agrotécnica Federal Antônio José Teixeira, Guanambi, BA, 2003-2004.

\begin{tabular}{|c|c|c|}
\hline Cultivares & Grupo genômico & Descrição \\
\hline Terra & $\mathrm{AAB}$ & $\begin{array}{l}\text { Cultivar de Plátano tipo Francês, porte alto, tardia, de alta produtividade, } \\
\text { resistente à Sigatoka-amarela e ao mal-do-Panamá e suscetível à Sigatoka-negra, } \\
\text { nematóides e broca-da-bananeira. }\end{array}$ \\
\hline $\begin{array}{c}\text { Terra- } \\
\text { Maranhão }\end{array}$ & $\mathrm{AAB}$ & $\begin{array}{l}\text { Cultivar de Plátano tipo Francês, mutante de Terra, porte alto, tardia, de alta } \\
\text { produtividade, resistente à Sigatoka-amarela e ao mal-do-Panamá e suscetível à } \\
\text { Sigatoka-negra, nematóides e broca-da-bananeira. }\end{array}$ \\
\hline Terrinha & $\mathrm{AAB}$ & $\begin{array}{l}\text { Cultivar de Plátano tipo Francês, mutante de Terra, porte médio, precoce, baixa } \\
\text { produtividade, resistente à Sigatoka-amarela e ao mal-do-Panamá, suscetível à } \\
\text { Sigatoka-negra. }\end{array}$ \\
\hline FHIA-21 & $\mathrm{AAAB}$ & $\begin{array}{l}\text { Híbrido tetraplóide de Plátano tipo Francês (AVP67 tipo Francês x SH3142), } \\
\text { desenvolvido pela Fundação Hondurenha de Investigação Agrícola e selecionado } \\
\text { pela Embrapa Mandioca e Fruticultura Tropical, porte médio, precoce, resistente } \\
\text { às sigatokas amarela e negra e ao mal-do-Panamá. }\end{array}$ \\
\hline D`Angola & $\mathrm{AAB}$ & $\begin{array}{l}\text { Cultivar de Plátano tipo Chifre, porte médio, precoce, de baixa produtividade, } \\
\text { resistente à Sigatoka-amarela e ao mal-do-Panamá e suscetível à Sigatoka-negra, } \\
\text { nematóides e broca-da-bananeira. }\end{array}$ \\
\hline
\end{tabular}

Tabela 2 - Valores médios de número de dias do plantio ao florescimento (NDF), altura da planta (APL), perímetro do pseudocaule (PPS), número de folhas vivas na época do florescimento (NFF) de cinco cultivares de bananeiras tipo Terra, em primeiro ciclo de produção, Guanambi, BA, $2004^{1}$.

\begin{tabular}{lcccc}
\hline \multicolumn{1}{c}{ Cultivares } & NDF $($ dias $)$ & APL $(\mathrm{cm})$ & PPS $(\mathrm{cm})$ & NFF (un) \\
\hline Terra & $455 \mathrm{a}$ & $495 \mathrm{a}$ & $121 \mathrm{a}$ & $17,9 \mathrm{a}$ \\
Terra-Maranhão & $448 \mathrm{a}$ & $491 \mathrm{a}$ & $117 \mathrm{a}$ & $17,6 \mathrm{a}$ \\
FHIA-21 & $336 \mathrm{~b}$ & $290 \mathrm{c}$ & $79 \mathrm{~b}$ & $14,3 \mathrm{~b}$ \\
D'Angola & $309 \mathrm{c}$ & $337 \mathrm{~b}$ & $76 \mathrm{~b}$ & $14,2 \mathrm{~b}$ \\
Terrinha & $303 \mathrm{c}$ & $316 \mathrm{bc}$ & $74 \mathrm{~b}$ & $13,4 \mathrm{~b}$ \\
\hline CV $(\%)$ & 2,57 & 5,93 & 4,81 & 5,40 \\
\hline
\end{tabular}

${ }^{1}$ Médias seguidas da mesma letra na coluna não diferem estatisticamente $(\mathrm{P}<0,05)$ pelo teste de Tukey. 
A maioria das cultivares apresentou altura maior que 3,0 m, exceto o híbrido FHIA-21 com valor de 2,90 m, que não diferiu estatisticamente da altura da cultivar Terrinha. As cultivares Terra e Terra-Maranhão apresentaram as maiores médias de altura, por isto, foram as que mais sofreram com o vento, que ocasionou o tombamento de algumas plantas e o fendilhamento de folhas sem, contudo, serem estas variáveis objeto de mensuração deste experimento. A variação em altura de planta foi de $290,12 \mathrm{~cm}$ a $495,10 \mathrm{~cm}$, sendo o menor valor apresentado pela FHIA-21, híbrido fruto de melhoramento dirigido para redução de porte.

Quando comparados aos valores obtidos por Donato et al. (2006), em experimento conduzido na mesma área, utilizando-se de variedades e híbridos dos mesmos grupos genômicos, percebe-se que esse descritor apresentou para as variedades do mesmo grupo genômico (AAB) valores bastante distintos, encontrando-se valores de 2,43 m para a cultivar Prata Anã e 3,23 m para a Pacovan naquele experimento, diferindo dos valores encontrados para as cultivares Terra e Terra-Maranhão (4,90 m em média), pois estas são de porte bastante elevado (Moreira, 1999), enquanto as cultivares Prata são de porte médio a alto, e aproximando-se dos valores médios encontrados para as cultivares D'Angola e Terrinha (3,09 e 3,03 m, respectivamente). Tal situação se deve, provavelmente, ao manejo da cultura, já que se trata dos mesmos genótipos.

A altura é um descritor importante do ponto de vista fitotécnico e de melhoramento, pois influi nos aspectos de densidade de plantio e manejo da cultura, interferindo diretamente na produção. Essa característica também determina a maior ou menor facilidade na operação de colheita, podendo também influenciar no tombamento de plantas adultas ou quebra do pseudocaule pela ação do vento. Além da altura de planta, o tombamento pode estar associado ao reduzido perímetro do pseudocaule e a produção de cachos grandes (Alves, 2001) e, no caso de cultivares tipo Terra, a vulnerabilidade a problemas radiculares advindos do ataque de nematóides e brocas. Para as condições locais do experimento, com predominância de ventos fortes, as cultivares mais altas apresentaram desvantagem quando comparadas com aquelas de menor porte, a exemplo do híbrido FHIA-21 que pode ser conduzido em espaçamentos mais adensados, sendo menos suscetíveis ao tombamento pela ação do vento.

O perímetro do pseudocaule oscilou entre 74,14 e $121,06 \mathrm{~cm}$, respectivamente, para as cultivares Terrinha e
Terra. Os valores médios em torno de $76 \mathrm{~cm}$ para esse descritor encontrados para as cultivares D'Angola e Terrinha e para o híbrido FHIA-21 aproximam-se bastante dos valores encontrados por Donato et al. (2006) que foi de $73 \mathrm{~cm}$ para as 13 cultivares do tipo Prata e Nanica, de vigor semelhante àquelas, enquanto que as plantas de Terra e Terra-Maranhão são muito vigorosas (Moreira, 1999), testadas em seu experimento no mesmo local. Os valores médios obtidos, entretanto, para o descritor ligado ao perímetro do pseudocaule diferiram das características gerais das cultivares descritas por Silva et al. (2000). A detecção de maiores perímetros do pseudocaule obtida nesse estudo pode estar ligada ao fato da cultura ter sido conduzida em solos de boa fertilidade e sob condição de irrigação, o que favoreceu um maior desenvolvimento vegetativo àquele descritor.

$\mathrm{O}$ vigor da planta em bananeira é refletido por caracteres morfológicos como altura da planta, perímetro do pseudocaule e número de folhas vivas. Em relação ao número de folhas vivas no florescimento e ao número de dias do plantio ao florescimento, foram detectadas diferenças entre as cultivares, sobressaindo a cultivar Terra, uma cultivar reconhecida como mais vigorosa e extremamente tardia. Em estudo conduzido por Morán (2001), o híbrido FHIA-21, sob ataque da Sigatoka-negra e sem qualquer controle químico, apresentou, no período final da floração, número total de folhas igual 12 unidades e 11 folhas funcionais, demonstrando a resistência desta cultivar àquela doença. Donato et al. (2006) encontraram para as cultivares do mesmo grupo genômico (AAB), valor médio igual a 18 folhas funcionais ao final do primeiro ciclo da cultura, aproximando-se bastante dos valores encontrados para as cultivares Terra e TerraMaranhão e diferindo das cultivares Terrinha e D’Angola e do híbrido FHIA-21, cuja média foi de 14 folhas. Entretanto, o local do experimento não apresenta a presença da Sigatoka, o que confirma o fato de ser o vento excessivo o responsável pela redução de folhas. Para o número de dias do plantio ao florescimento, os valores, variando de 225 dias para a Prata-Anã e 242 dias para a cultivar Pacovan, encontrados por Donato et al. (2006), foram significativamente inferiores aos do atual experimento, cujas, médias, foi de 450 dias para as cultivares Terra e Terra-Maranhão e de 330 dias para as demais, comprovando a característica de ciclo longo deste tipo de bananas.

Na Tabela 3, estão descritos os resultados obtidos para as características avaliadas na época da colheita que evidenciaram diferenças significativas entre as cinco cultivares. 
Tabela 3 - Valores médios de peso do cacho (PCA), peso da ráquis (PRA), peso das pencas (PPE), número de pencas (NPE), número de frutos (NFR), comprimento externo do fruto (CEF), diâmetro lateral do fruto (DLF), número de dias do plantio a colheita (NDC), intervalo do florescimento a colheita (IFC), número de folhas vivas na colheita (NFC) e número de frutos por cacho (NFR) para cinco cultivares de bananeiras tipo Terra em primeiro ciclo de produção, Guanambi - BA, 2004'.

\begin{tabular}{lcccccccccc}
\hline Cultivares & $\begin{array}{r}\text { PCA } \\
(\mathrm{kg})\end{array}$ & $\begin{array}{r}\text { PRA } \\
(\mathrm{kg})\end{array}$ & $\begin{array}{r}\text { PPE } \\
(\mathrm{kg})\end{array}$ & $\begin{array}{c}\text { CEF } \\
(\mathrm{cm})\end{array}$ & $\begin{array}{c}\text { DLF } \\
(\mathrm{mm})\end{array}$ & $\begin{array}{r}\text { NPE } \\
(\mathrm{un})\end{array}$ & $\begin{array}{r}\text { NDC } \\
(\text { dias })\end{array}$ & $\begin{array}{c}\text { IFC } \\
(\text { dias })\end{array}$ & $\begin{array}{r}\text { NFC } \\
(\text { un })\end{array}$ & $\begin{array}{r}\text { NFR } \\
(\text { un })\end{array}$ \\
\hline Terra & $40,8 \mathrm{a}$ & $3,7 \mathrm{a}$ & $37,2 \mathrm{a}$ & $23,6 \mathrm{~b}$ & $36,5 \mathrm{~b}$ & $12 \mathrm{a}$ & $548 \mathrm{a}$ & $100 \mathrm{a}$ & $9 \mathrm{c}$ & $216 \mathrm{a}$ \\
Terra-Maranhão & $36,5 \mathrm{a}$ & $3,0 \mathrm{a}$ & $33,6 \mathrm{a}$ & $22,2 \mathrm{~b}$ & $36,7 \mathrm{~b}$ & $11 \mathrm{a}$ & $544 \mathrm{a}$ & $97 \mathrm{a}$ & $\begin{array}{c}10 \mathrm{bc} \\
186 \mathrm{~b}\end{array}$ \\
FHIA-21 & $20,3 \mathrm{~b}$ & $3,1 \mathrm{a}$ & $17,2 \mathrm{~b}$ & $23,6 \mathrm{~b}$ & $35,2 \mathrm{~b}$ & $7 \mathrm{~b}$ & $407 \mathrm{~b}$ & $71 \mathrm{~b}$ & $\begin{array}{c}11 \mathrm{bc} \\
88 \mathrm{c}\end{array}$ \\
D'Angola & $12,0 \mathrm{c}$ & $1,3 \mathrm{~b}$ & $10,7 \mathrm{c}$ & $26,1 \mathrm{a}$ & $40,6 \mathrm{a}$ & $7 \mathrm{~b}$ & $365 \mathrm{c}$ & $56 \mathrm{c}$ & $14 \mathrm{a}$ & $36 \mathrm{~d}$ \\
Terrinha & $20,0 \mathrm{~b}$ & $1,8 \mathrm{~b}$ & $18,3 \mathrm{~b}$ & $22,9 \mathrm{~b}$ & $34,4 \mathrm{~b}$ & $8 \mathrm{~b}$ & $385 \mathrm{bc}$ & $81 \mathrm{~b}$ & $12 \mathrm{ab}$ & $93 \mathrm{c}$ \\
\hline CV $(\%)$ & 9,77 & 15,81 & 10,24 & 4,64 & 4,67 & 5,96 & 2,86 & 9,37 & 9,64 & 8,34 \\
\hline
\end{tabular}

${ }^{1}$ Médias seguidas da mesma letra na coluna não diferem estatisticamente $(\mathrm{P}<0,05)$ pelo teste de Tukey.

O peso do cacho oscilou de 12,0 a $40,8 \mathrm{~kg}$ para as cultivares D’Angola e Terra, respectivamente. O híbrido FHIA-21 superou em quase $10 \mathrm{~kg}$ o peso do cacho das cultivares D’Angola e Terrinha, uma vez que o mesmo teve melhoramento dirigido também para produtividade, embora estes genótipos tenham apresentado ciclos de produção próximos, cujos valores foram 407, 365 e 385 dias, respectivamente.

O comprimento do fruto é utilizado para fins de classificação, constituindo característica essencial para o melhoramento de bananeiras, quando se trata da qualidade do fruto, haja vista que o preço de venda às vezes depende do tamanho da banana. O comprimento do fruto variou de 26,1 cm para D’Angola a 22,2 cm para a Terra-Maranhão. Cruz (2007), nas condições das Filipinas, e para o híbrido FHIA-21, relata comprimento médio do fruto igual a 18,3 $\mathrm{cm}$, inferior ao encontrado neste trabalho cuja média foi de $23,6 \mathrm{~cm}$, o que se explica pelo fato do experimento ter sido conduzido em solos de boa fertilidade e sob condição de irrigação.

O diâmetro do fruto indica o ponto de colheita para bananas (Jaramillo, 1982; Soto Ballestero, 1992; Alves et al., 1997; Moreira, 1999), sendo também utilizado para classificação do fruto da bananeira, muito embora, no caso dos plátanos, o pleno desenvolvimento fisiológico é caracterizado pela observação visual da coloração rosada da polpa dos frutos da primeira penca, bem como pelo desaparecimento das quinas ou angulosidades da superfície dos frutos, exceto para as cultivares Terra e TerraMaranhão, cujas angulosidades permanecem salientes mesmo depois dos frutos maduros, devendo-se observar, neste caso, o máximo desenvolvimento do diâmetro dos frutos localizados no meio do cacho (Alves, 2001). Os valores dessa característica variaram, neste trabalho, de 40,56 mm na cultivar D’Angola a 34,42 $\mathrm{mm}$ para a Terrinha.

Quanto à característica número de pencas, a cultivar Terra destacou-se das demais no primeiro ciclo, igualandose estatisticamente à Terra-Maranhão. A FHIA-21, D’Angola e Terrinha apresentaram, em média, três pencas a menos que a Terra e Terra Maranhão. Santos et al. (2006) observaram, para a cultivar FHIA-21, valores médios de 6 pencas/cacho. Silva et al. (2008) relatam para as cultivares Terra e D'Angola número de pencas igual a 10 e sete, respectivamente, conforme esperado, haja vista estas cultivares serem altamente produtivas.

As cultivares Terra e Terra-Maranhão, sob a mesma lâmina de irrigação, apresentaram, o maior ciclo, com médias de 548 e 544 dias, respectivamente. O ciclo apresenta fundamental importância no melhoramento genético da bananeira, pois é um caráter que mostra a expressão da precocidade. A redução do número de dias necessários para a emissão do cacho traz expectativas de retorno do investimento inicial.

Para o número de folhas avaliadas na colheita, a Terra e a Terra-Maranhão apresentaram as menores médias. Não houve diferença entre FHIA-21 e a Terra-Maranhão quanto ao número de folhas na colheita. A perda de folhas pode ter sido influenciada pela maior ação do vento nas cultivares Terra e Terra-Maranhão, semelhante ao observado por Donato et al. (2006) para as cultivares de porte alto do tipo Pacovan.

Para o número de frutos por cacho, Silva et al. (2008), relatam dados médios para as condições de Cruz das Almas, Bahia, de 160 e 40 frutos por cacho, para as 
cultivares Terra e D’Angola, respectivamente, diferindo significativamente do valor encontrado neste experimento para a cultivar Terra, que foi de 216 frutos por cacho e aproximando-se do valor medido para a cultivar D’Angola que foi de 36 frutos por cacho, provavelmente em função das condições locais do experimento em Guanambi (irrigação e maior aporte de fertilizantes).

Em termos gerais, pode-se resumir que foram encontradas grandes diferenças entre as cultivares, tanto em vigor como em produção. Torna-se possível estabelecer que as cultivares Terra e Terra-Maranhão apresentaram maiores ciclos e foram as mais produtivas, porém com sérios problemas de condução da cultura em função do maior porte, como, por exemplo, tombamento de plantas e ataque de doenças. Por outro lado, as cultivares D’Angola e Terrinha e o híbrido FHIA-21, apresentaram características de menor porte, maior precocidade e menores produções em primeiro ciclo.

Excetuando a cultivar D'Angola que apresentou baixa produtividade, é possível para o híbrido FHIA-21 e a cultivar Terrinha a obtenção de maiores produções, haja vista o menor porte de ambas, possibilitando plantios mais adensados, já que o espaçamento utilizado no experimento é o padrão para as bananas tipo Terra de porte mais alto. $\mathrm{O}$ híbrido FHIA-21 apresenta-se como um genótipo promissor pelas características de porte médio, precocidade e resistência à Sigatoka-negra, embora seja necessária a realização de estudo de adequação mercadológica e econômico-financeira da atividade para comprovar o fato.

\section{CONCLUSÕES}

Os resultados obtidos neste trabalho qualificam as cultivares Terra, Terra-Maranhão, Terrinha e o híbrido FHIA21 como promissoras para serem incorporadas aos sistemas de produção dos Perímetros Irrigados de regiões semiáridas;

As cultivares Terra e Terra-Maranhão são mais produtivas, porém mais altas e de ciclo mais longo quando comparadas a cultivar Terrinha e ao híbrido FHIA-21.

\section{REFERÊNCIAS BIBLIOGRÁFICAS}

ALVES, E.J. Cultivo da bananeira tipo Terra. Cruz das Almas: Embrapa-CNPMF, 2001. 176p.

ALVES, E.J.; LIMA, M.B. Práticas culturais. In: ALVES, E.J. Cultivo da bananeira Tipo Terra. Cruz das Almas: Embrapa-CNPMF, 2001. p.57-70.

ALVES, E.J.;- MEDINA, V.M.; OLIVEIRA, M. de A. Colheita e manejo pós-colheita. In: ALVES, E.J. (Org.). A cultura da banana: aspectos técnicos socioeconômicos e agroindustriais. Brasília: Embrapa-SPI, 1997. P.453-486.

BERNARDO, S.; SOARES, A.A.; MANTOVANI, E.C. Manual de irrigação. 8.ed. Viçosa, MG: UFV, 2006. 625p.

BORGES, A.L.; SILVA, T.O. da; CALDAS, R.C.; ALMEIDA, I.E. de.- Adubação nitrogenada para bananeira- 'Terra' (Musa sp. AAB, subgrupo Terra). Revista Brasileira de Fruticultura, Jaboticabal, v.24, n.1, p.189-193, 2002.

COMPANHIA DE DESENVOLVIMENTO DOS VALES DO SÃO FRANCISCO E DO PARNAÍBA. Disponível em: 〈www.codevasf.gov.brì. Acesso em: 7 set. 2007.

COELHO, E.F.; OLIVEIRA, S.L.; COSTA, E.L.. Irrigação da bananeira. In: SIMPÓSIO NORTEMINEIRO SOBRE A CULTURA DA BANANA, 1 ., 2001, Nova Porteirinha. Anais... Montes claros: Unimontes, 2001. P.91-101.

CRUZ, F.S.; GUECO, L.S.; DAMASCO, O.P.; HUELGAS, V.C.; BANASIHAN, I.G.; LLADONES, R.V.; BERGH, I.; MOLINA, A.B. Catalogue of introduced and local banana cultivars in the Philippines: results of a demonstration trial by the Institute of Plant Breeding. Los Baños: University of the Philippines, 2007. 63p.

DADZIE, B.K.; ORCHARD, J.E. Evaluacíon rutinaria postcosecha de híbridos de bananos y plátanos: criterios y métodos: guias técnicos INIBAP 2. Roma: Red Internacional para el Mejoramiento del Banano y el Plátano, 1997.

DONATO, S.L.R. Comportamento de variedades e híbridos de bananeira (Musa spp.), em primeiro ciclo de produção no Sudoeste da Bahia, Região de Guanambi. 2003. 115f. Dissertação (Mestrado em Ciência e Tecnologia de Sementes)-Faculdade de Agronomia "Eliseu Maciel", Universidade Federal de Pelotas, Pelotas, 2003.

DONATO, S.L.R.; SILVA, S. de O.; LUCCA FILHO, O.A.; LIMA, M.B.; DOMINGUES, H.; ALVES, J.S.

Comportamento de variedades e híbridos de bananeira (Musa spp.), em dois ciclos de produção no Sudoeste da Bahia. Revista Brasileira de Fruticultura, Jaboticabal, v.28, n.1, p.139-144, abr. 2006. 
DOORENBOS, J.; KASSAM, A.H. Efeito da água no rendimento das culturas. Campina Grande: UFPB, 1994 306p (Estudos FAO: Irrigação e Drenagem, 33).

FOOD AND AGRICULTURAL ORGANIZATION. Disponível em: 〈http://apps.fao.org/page/collections $>$. Acesso em: 5 jun. 2008.

JARAMILLO, R.C. Las principales características morfológicas del fruto de banano, variedade Cavendish (Musa AAA) em Costa Rica. [S.1.]: Upeb-Impretex-, 1982. 42p.

MOREIRA, R.S. Banana, teoria e prática de cultivo. 2.ed. São Paulo: Fundação Cargill, 1999. CD-ROM.
SILVA, S. de O. e; PEREIRA, L.V.; RODRIGUES, M.G.V. Bananicultura irrigada: inovações tecnológicas: variedades. Informe Agropecuário, Belo Horizonte, v.29, n.245, p.78-83. Jul./ago. 2008.

SILVA, S. de O. e; ROCHA, S.A.; ALVES, E.J.; CREDICO, M.D.; PASSOS, A.R. Caracterização morfológica e avaliação de cultivares e híbridos de bananeira. Revista Brasileira de Fruticultura, Jaboticabal, v.22, n.2, 2000.

SOTO BALLESTERO, M. Bananos: cultivo e comercializacion. 2.ed. San José: LIL, 1992. 674p. 